\title{
-Original-
}

\section{Isolation and morphological characterization of ovine amniotic fluid mesenchymal stem cells}

\author{
Yunyun TIAN ${ }^{1) *}$, $\mathrm{Li} \mathrm{TAO}^{1) *}$, Siriguleng $\mathrm{ZHAO}^{1)}$, Dapeng $\mathrm{TAI}^{2)}$, Dongjun $\mathrm{LIU}^{2) \#}$, and Pengxia $\mathrm{LIU}^{1) \#}$ \\ 1) College of Life Sciences, Inner Mongolia University, Inner Mongolia, Hohhot 010021, P.R. China \\ ${ }^{2)}$ Key Laboratory of Mammalian Reproductive Biology and Biotechnology Ministry of Education, Inner Mongolia \\ University, Inner Mongolia, Hohhot 010021, P.R.China
}

\begin{abstract}
Mesenchymal stem cells (MSCs) are one of the most promising cell populations for tissue engineering and regenerative medicine. Of utmost importance to MSC research is identification of MSC sources that are easily obtainable and stable. Several studies have shown that MSCs can be isolated from amniotic fluid. The sheep is one of the main types of farm animal, and it has many biophysical and biochemical similarities to humans. Here, we obtained MSCs from ovine amniotic fluid and determined the expansion capacity, surface and intracellular marker expression, karyotype, and multilineage differentiation ability of these ovine amniotic fluid mesenchymal stem cells (oAFMSCs). Moreover, expression levels of differentiation markers were measured using reverse transcription-qPCR (RT-qPCR). Our phenotypic analysis shows that the isolated oAF-MSCs are indeed MSCs.
\end{abstract}

Key words: amniotic fluid, isolation, mesenchymal stem cells, morphological characterization, sheep

\section{Introduction}

Mesenchymal stem cells (MSCs) are non-hematopoietic stromal cells that can be isolated from various tissues including the bone marrow, cartilage, synovium, adipose tissue, placenta, umbilical blood, and vasculature [31, 32]. MSCs are self-renewing, multipotent progenitor cells, that can differentiate into multiple cell types including osteogenic, chondrogenic, adipogenic, and myogenic cells $[16,20,21,48]$. They are considered to be one of the most promising cell sources for therapeutic drugs and tissue engineering. Advantages of their use include safety, convenient collection procedure, reduced rejection potential, and transplantation with less risk and attrition in the donor $[3,36,44]$. MSCs isolated from fetal tissues may be more plastic and stable and offer an available alternative to their recipient [27].

Isolation of MSCs from amniotic fluid has been reported for a number of mammals including human, buffalo, and horse $[5,10,11,14,19,24]$. Amniotic fluidderived stem (AFS) cells isolated during pregnancy for prenatal genetic tests are an efficient source of cells with therapeutic potential [10]. AFS cells are widely multipotent, express some pluripotency markers, and can be differentiated within the tissues of the three germ layers [8]. Their properties, such as low immunogenicity, the inability to form tumors, easy accessibility, and the absence of ethical problems associated with their use, make them ideal candidates for regenerative medicine [4, 29].

The sheep is one of the main types of farm animal and

(Received 2 April 2015 / Accepted 19 October 2015 / Published online in J-STAGE 27 November 2015)

Address corresponding: D. Liu, Key Laboratory of Mammalian Reproductive Biology and Biotechnology Ministry of Education, Inner Mongolia University, Inner Mongolia, Hohhot 010021, P.R.China/ P. Liu, College of Life Sciences, Inner Mongolia University, Inner Mongolia, Hohhot 010021, P.R.China

*These authors contributed equally to the work.

\#These authors also contributed equally to the work. PX Liu, DJ Liu and DP Tai conceived and designed the experiments. YY Tian, L Tao, and S Zhao performed the experiments. YY Tian, L Tao, and S Zhao analyzed the data. YY Tian and PX Liu wrote the paper.

(C)2016 Japanese Association for Laboratory Animal Science 
has many biophysical and biochemical similarities to humans. Of its many unique features, its size, character, and similarities to humans make it a reasonable tool for preclinical evaluation and optimization of extensive biotechnological developments $[18,35]$. The sheep is also a reliable animal model for chondrogenesis research both in vivo [46] and in vitro [47]. Moreover, large animals form an optimal preclinical model in which to study various diseases, such as bone disease. In this context, amniotic fluid-derived mesenchymal stem cells from sheep (oAFMSCs) used in allotransplantation of injured Achilles tendon led to matrix organization and tissue regeneration $[6,7]$.

Isolation and characterization of oAF-MSCs has previously been reported [26]. Shaw et al. also found that oAF-MSCs could differentiate into osteogenic and adipogenic cells in 2011. The cells they identified were nucleofected with a GFP reporter gene in a transient and stable prolonged manner and maintain the features of pluripotent stem cells [38]. Furthermore, oAF-MSCs have been used in tissue renovation such as the repair of diaphragmatic tendon [42] and prenatal tracheal reconstruction [17].

Our lab concentrate on transgenic breeding of sheep and goats $[41,45]$. As the majority of attempts to establish ESC lines from large animals, especially ungulate mammals, have failed, we tried to use more suitable cells as the donor of nuclei, such as the oAF-MSCs we just isolated. We also successfully reprogrammed sheep fibroblasts into pluripotent cells under drug-inducible expression of mouse-derived defined factors in 2011 [23]. But the efficiency was low. Li et al. generated induced pluripotent stem cells from human amniotic fluid cells by reprogramming with two factors under feederfree conditions [33]. We attempted to increase the inducing efficiency by looking for a more suitable cell type.

Here, we isolated MSCs from ovine amniotic fluid and systematically characterized their multilineage differentiation ability, especially the variation tendency of differentiation marker gene expression. The oAF-MSCs were expanded until the 3rd passage and then frozen. Subsequently, we measured the proliferation capacity of all samples at the 5th and 20th passage, and examined the karyotype of 20th passage cells, and we found that the chromosome number remained normal. After thawing, passage 3 cells were expanded by two more passages, and we then analyzed the expression of cell surface and intracellular markers and potential to
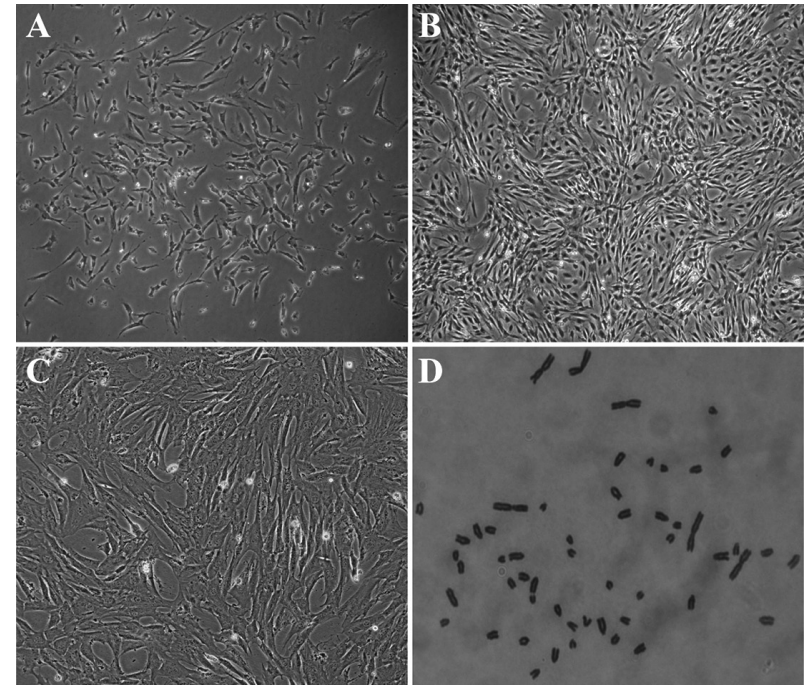

Fig. 1. Karyotype analysis of AF-MSCs obtained from the ovine fetus. (A) Primary cultured cells of the sample. (B) Morphology of oAF-MSCs at passage 5. (C) Morphology of oAF-MSCs after culture in vitro for 20 passages. (D) Karyotype analysis of passage 20 diploid cells. The normal chromosome complement of 54 pairs was detected.

differentiate into osteoblasts, chondrocytes, and adipocytes. Expression levels of differentiation markers were measured using quantitative reverse transcription PCR (RT-qPCR).

\section{Materials and Methods}

\section{Animals}

Pregnant sheep were obtained from the Experimental Animal Center at Inner Mongolia University, Hohhot, China. All studies were performed with the approval of the Experimental Animal Committee of Inner Mongolia University.

\section{Isolation and cultivation of oAF-MSCS}

Cells were selected solely on the ability to adhere to plastic. Isolated cells attached to plastic culture dishes more readily (Fig. 1). Under anesthesia, amniotic fluid samples were obtained by cesarean section from pregnant sheep at the full-term stage of gestation. Samples were centrifuged at $230 \times g$ for $5 \mathrm{~min}$. Cells were then resuspended at a density of $5 \times 10^{4} / \mathrm{ml}$ in MSC-specific medium containing DMEM-F12 (HyClone; Thermo Scientific, Beijing, China), 10\% FBS (Gibco, Carlsbad), $1 \%$ GlutaMAX (Gibco), $1 \mu \mathrm{M}$ dexamethasone (DSMS; Solarbio, Beijing, China), $2 \mathrm{ng} / \mathrm{ml}$ fibroblast growth 
factor-basic (bFGF; PeproTech Inc., Rocky Hill, NJ, USA), $10 \mathrm{ng} / \mathrm{ml}$ epidermal growth factor (EGF, Sigma, St. Louis, MO, USA), and 1\% penicillin-streptomycin and plated in $9 \mathrm{~cm}$ diameter dishes in a humidified atmosphere with $5 \% \mathrm{CO}_{2}$ at $37^{\circ} \mathrm{C}$. The culture medium was replaced every 3 days. Once adherent cells reached 80-90\% confluency, they were harvested using $0.25 \%$ trypsin/1 mM EDTA solution (Sigma) and subcultured at a ratio of 1:2. Third-passage cells were frozen for testing.

\section{Karyotype analysis}

Passage 20 oAF-MSCs (at 80\% confluency) were used for karyotype analysis. Cells were treated with $0.1 \mathrm{mg} /$ $\mathrm{ml}$ colchicine and incubated in a humidified atmosphere with $5 \% \mathrm{CO}_{2}$ at $37^{\circ} \mathrm{C}$ for $3.5 \mathrm{~h}$. Cells were harvested using $0.25 \%$ trypsin/ $1 \mathrm{mM}$ EDTA solution, centrifuged at $230 \times \mathrm{g}$ for $5 \mathrm{~min}$, mixed with $8 \mathrm{ml} 0.075 \mathrm{M} \mathrm{KCl}$, and incubated at $37^{\circ} \mathrm{C}$ for $30 \mathrm{~min}$. Next, cells were fixed in methyl alcohol/ethanoic acid (3:1) for $30 \mathrm{~min}$ incubations and then resuspended in $1 \mathrm{ml}$ methyl alcohol/ethanoic acid (3:1). Chromosome karyotypes were determined by dropping the cell suspension onto prechilled glass slides [15].

\section{Immunofluorescence staining of surface markers and} intracellular marker

Passage 5 oAF-MSCs (at 60-80\% confluency) cultured on coverslips in 6-well culture plates, were washed with PBS. After fixation for $30 \mathrm{~min}$ at room temperature in $2 \%$ paraformaldehyde/PBS ( $\mathrm{pH} 7.4$, Sigma) fixing solution, only the intracellular marker group needed permeation with 1\% Triton for 25-30 min. Cells were blocked with blocking solution (1\% BSA in PBS) for 1 $\mathrm{h}$ at room temperature and then incubated overnight with primary antibodies at $4{ }^{\circ} \mathrm{C}$. The primary antibodies included anti-mouse CD29, CD13, CD44, CD45, CD90, CD106, and OCT4 (Boster Biological Technology, Wuhan, China), and all were diluted with PBS at 1:100. Coverslips for negative controls were incubated with PBS. After washing with PBS, all coverslips were treated with sheep anti-rabbit IgG secondary antibody (Boster Biological Technology) for $2 \mathrm{~h}$, and then the slides (including negative controls) were counterstained with 4',6-diamidino-2-phenylindole (DAPI; SouthernBiotech, Birmingham, AL, USA) for $30 \mathrm{~min}$.

\section{Cell proliferation assay for oAF-MSCs}

To determine the growth characteristics of oAF-MSCs, passage 5 and 20 cells were seeded at a density of 2,000 cells/ml in 96-well plates and cultured in MSC-specific medium for up to 7 days. Next, $10 \mu \mathrm{l} \mathrm{CCK-8} \mathrm{(Cell}$ Counting Kit-8, Beyotime Biotechnology, China) was added into each well per day and incubated at $37^{\circ} \mathrm{C}$ for $4 \mathrm{~h}$. Light absorption values were determined at wavelengths of 450 and $650 \mathrm{~nm}$ using a Thermo Scientific Varioskan Flash.

\section{Differentiation procedures}

To examine the differentiation capabilities of oAFMSCs, they were subjected to specific induction protocols. An equal number of cells were maintained in expansion medium as the negative control. All cells were cultured for up to 21 days with medium changes every 3-4 days.

\section{Osteogenic induction}

The ability of oAF-MSCs to differentiate into osteoblasts was demonstrated using silver nitrate $\left(\mathrm{AgNO}_{3}\right)$. Briefly, oAF-MSCs were seeded at a density of 2,000 cells/ml. After $24 \mathrm{~h}$, expansion medium was replaced with osteogenic differentiation medium composed of Iscove's modified DMEM (IMDM; HyClone; Thermo Scientific, Beijing, China), 10\% FBS (HyClone; Thermo Scientific, Beijing, China), 1\% GlutaMAX, $0.1 \mu \mathrm{M}$ DSMS, $10 \mathrm{mM} \beta$-glycerophosphate disodium salt hydrate (Sigma), and $0.05 \mathrm{mM}$ vitamin C (Sigma). On day 21 , osteogenic cultures were fixed with $4 \%$ paraformaldehyde/PBS for $40 \mathrm{~min}$, and treated with $20 \mathrm{ng} / \mathrm{ml}$ $\mathrm{AgNO}_{3}$ for $30 \mathrm{~min}$. After washing with PBS, cultures were placed under UV light for $2 \mathrm{~h}$, stained with hematoxylin (Sigma) for $10 \mathrm{~min}$, and then washed with PBS. Following removal of $1 \%$ hydrochloric acid/alcohol, $0.25 \%$ ammonia spirit (Yongda, Tianjin, China) was added until cultures turned blue.

\section{Chondrogenic induction}

OAF-MSCs were seeded at a density of 2,000 cells/ $\mathrm{ml}$, and after $24 \mathrm{~h}$, expansion medium was replaced with differentiation chondrogenic medium composed of IMDM, 10\% FBS, 1\% GlutaMAX, $0.1 \mu \mathrm{M}$ DSMS, 50 $\mu \mathrm{g} / \mathrm{ml}$ vitamin $\mathrm{C}$, and $10 \mathrm{ng} / \mathrm{ml}$ transforming growth factor beta (TGF- $\beta$; PeproTech, Rocky Hill, NJ, USA). On day 21, chondrogenic cultures were washed with PBS and fixed with $10 \%$ formaldehyde for $45 \mathrm{~min}$. Cultures 
Table 1. Primers used in this study

\begin{tabular}{llllr}
\hline Gene & Accession No. & \multicolumn{1}{c}{ Forward primer } & Reverse primer & $\begin{array}{c}\text { Product } \\
\text { length (bp) }\end{array}$ \\
\hline GAPDH & U94889.1 & ACCACTGTCCACGCCATCAC & GCCTGCTTCACCACCTTCTT & 269 \\
$B G L A P$ & DQ418490 & CCCAGGAGGGAGGTGTGTG & CTAGACCGGGCCGTAGAAGC & 99 \\
$B G N$ & NM-001009201.1 & GAACGGGAGCCTGAGTTTTCT & ACTTTGGTGATGTTGTTGGTGG & 138 \\
$L U M$ & NM_173934.1 & AGAATTAACGAAAGCAGGGTCAAG & GCCAAGAGGAGAGGAAACACA & 84 \\
$P P A R G$ & NM_001100921.1 & ACGGGAAAGACGACAGACAAA & AAACTGACACCCCTGGAAGATG & 150 \\
$S C D$ & AJ001048.1 & GCTGGCACATCAACTTTACCAC & TTTCCTCTCCAGTTCTTTCATCC & 123 \\
\hline
\end{tabular}

GenBank accession numbers of the sequences used for primer design. Primer sequences and product lengths are shown.

were then washed with pure water twice and treated with Alcian Blue 8GX (Aladdin, Shanghai, China) for $30 \mathrm{~min}$.

\section{Adipogenic induction}

The ability of oAF-MSCs to differentiate into adipoblasts was demonstrated using oil red O (Ziyi Reagent Factory, Shanghai, China). Cultures were treated with adipogenic induction medium composed of IMDM, $10 \%$ FBS, 1\% GlutaMAX, $0.1 \mu$ M DSMS, 0.5 mM 3-isobutyl1-methylxanthine (Sigma), $5 \mu \mathrm{g} / \mathrm{ml}$ insulin (Sigma), and $60 \mu \mathrm{M}$ indomethacin (Sigma).

\section{Total RNA isolation and RT- $q P C R$}

The potential of oAF-MSCs to differentiate into osteoblasts, chondrocytes, and adipocytes was determined by RT-qPCR analysis of expression levels of differentiation markers (Table 1). The marker genes have been reported previously [19]. RT-qPCR primers were synthesized by Takara Bio, Shiga, Japan (Table 1). Total RNA was extracted from fully digested cells using TRIzol (Invitrogen Life Technologies, Carlsbad, CA, USA), according to the manufacturer's instructions. To eliminate potential genomic DNA interference, RNA samples were treated with $15 \mathrm{U}$ of DNase I (RNase-free; Takara Bio, Shiga, Japan). First-strand cDNA synthesis was performed on both differentiated and control oAFMSC cultures using a PrimeScript ${ }^{\mathrm{TM}}$ RT Master Mix kit (Takara Bio). RT-qPCR was performed using SYBR ${ }^{\circledR}$ Premix Ex Taq ${ }^{\text {TM }}$ II (Takara Bio) and an Analytik Jena qTower 2.0. Relative gene expression levels were normalized to GAPDH and calculated using the $2^{-\triangle \Delta \mathrm{Ct}}$ method.

\section{Image analysis}

Light and epifluorescence microscopy were performed using a Leica DMI3000 B microscope (Leica, Heer- brugg, Switzerland) with appropriate filters. Images were captured using Leica Application Suite V4. Growth curve images were created using Origin 8.6 (http://www.originlab.com/)

\section{Statistical analysis}

Statistical analysis was performed using the Pearson correlation test in IBM SPSS Statistics 19.0. $P$ values $<0.05$ were considered statistically significant $\left({ }^{*} P<0.05\right.$ and ${ }^{*} P<0.01$ indicate statistically significant differences).

\section{Results}

\section{Phenotype and karyotype analysis}

In subculture of oAF-MSCs, we found that the adherence of passage 20 cells was enhanced, increasing their digestion time from $1 \mathrm{~min}$ to 3 or $4 \mathrm{~min}$. The chromosomes of 50 cells were counted. The karyotype of 46 diploid oAF-MSCs remained normal, with 54 chromosome pairs, twice that of somatic cells (Fig. 1).

\section{Expression of MSC surface markers}

To characterize oAF-MSCs, we analyzed the expression of six MSC surface markers and one intracellular marker by immunofluorescence staining. The oAF-MSCs were positive for CD13, CD29, CD44, CD90, CD106, and OCT4 and negative for CD45 (Fig. 2).

\section{Expansion capacity}

Growth curves of passage 5 showed significantly high expansion capacity on days 1-7. After the 1 st day, the cells began to grow and entered a plateau phase on the 5th day (Fig. 3A). But the passage 20 showed lower expansion capacity (Fig. 3B). 

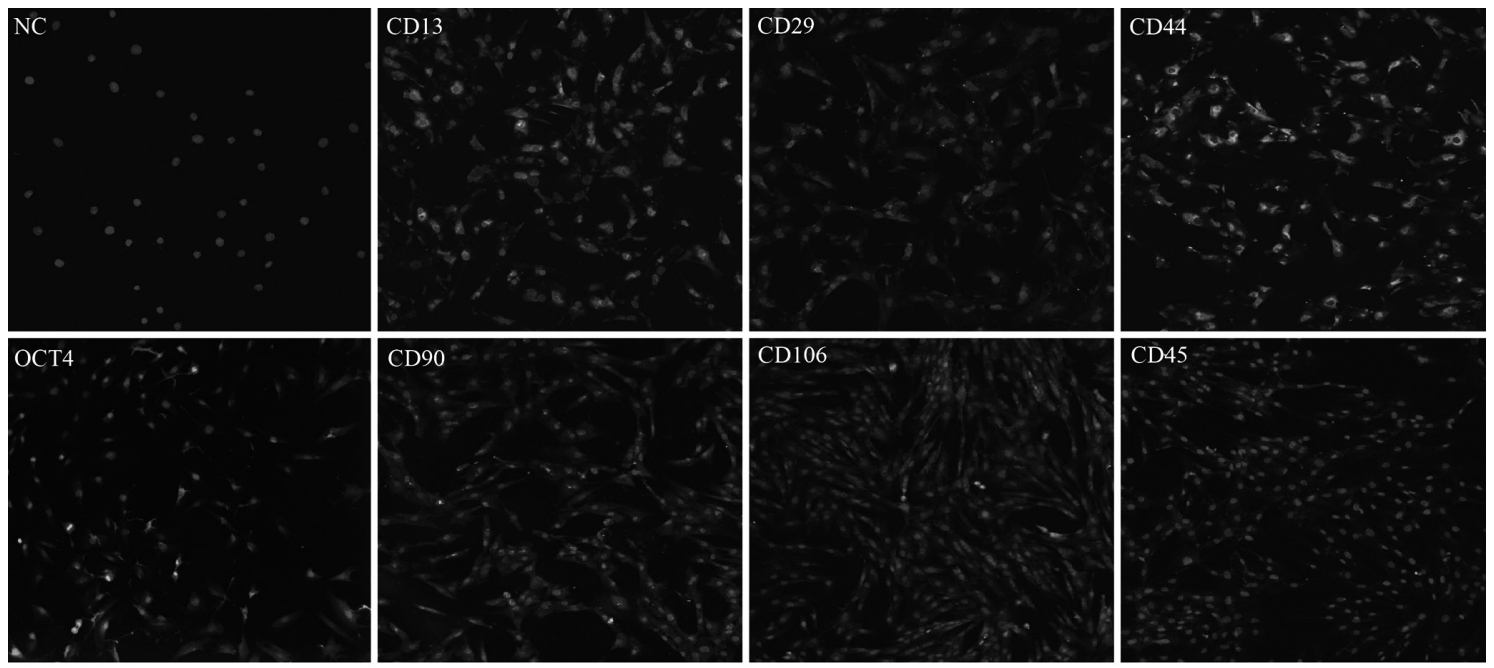

Fig. 2. Determination of specific MSC surface markers in oAF-MSCs. Specific markers were detected by immunocytochemistry (ICC). Antibodies against CD13, CD29, CD44, CD90, CD106, and OCT4 showed positive staining, which was indicated by green fluorescence (FITC). CD45 was negative. NC, negative control. Nuclei were stained with DAPI (blue fluorescence).
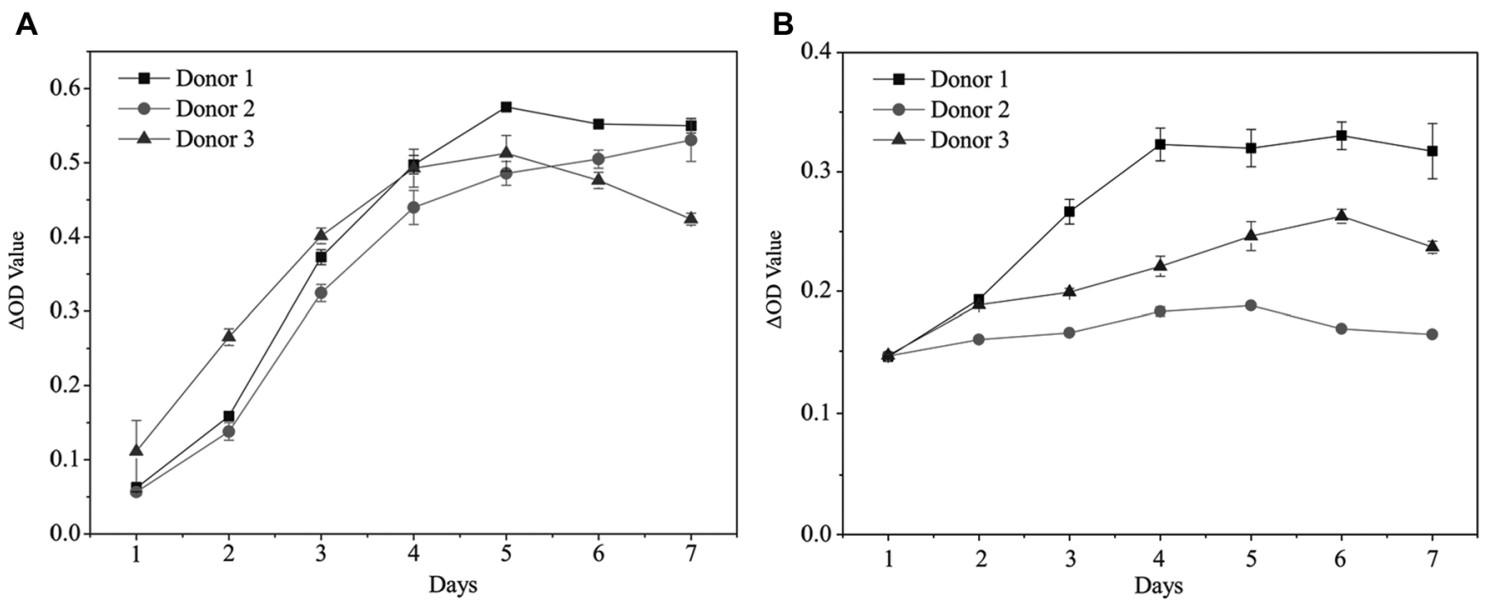

Fig. 3. Growth curves of oAF-MSCs at passage 5. The expansion capacity of oAF-MSCs is shown. Cells at passage 5 from the three samples obtained began to grow after the 1st day, and entered a plateau phase on the 5th day (A), and passage 20 cells showed decreased proliferative ability (B).

\section{Differentiation capacity}

Deposition of calcium salt and formation of calcium nodes were also apparent (Fig. 4A). In chondrogenic media, oAF-MSCs showed stronger Alcian Blue staining (Fig. 4C). Under adipogenic conditions, oAF-MSCs exhibited microscopic cytoplasmic lipid droplets (Fig. 4E).

The expression of adipogenic, osteogenic, and chondrogenic markers were analyzed on days 7,14 , and 21 post induction. Expression patterns of five specific markers detected by RT-qPCR in control and differentiated samples are shown (Fig. 5). The relative expression of each sample at the three test points was calculated for three independent experimental replicates. Fitted lines show the correlation between gene expression patterns and induction time for each sample. Expression of the osteogenic marker, bone gamma-carboxyglutamate (gla) protein (BGLAP; or osteocalcin) increased throughout 

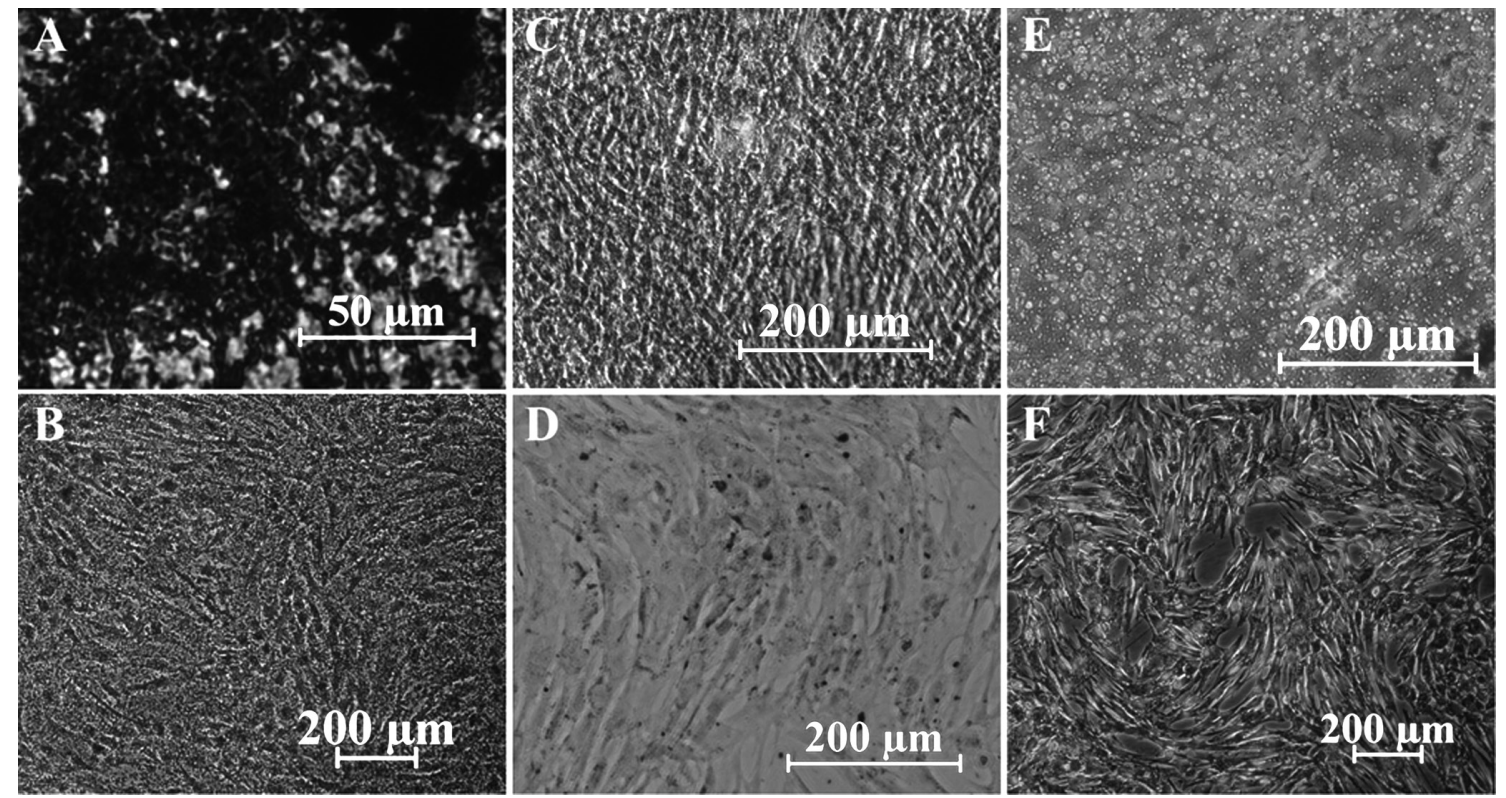

Fig. 4. Staining for osteogenic, chondrogenic, and adipogenic differentiation of oAF-MSCs. Deposition of calcium salt and formation of calcium nodes was observed (A). Cells in chondrogenic media displayed stronger Alcian Blue staining than negative controls (C). Cells under adipogenic induction showed cytoplasmic lipid droplets (E). B, D, and $\mathrm{F}$ represent negative controls for each differentiated sample, respectively.
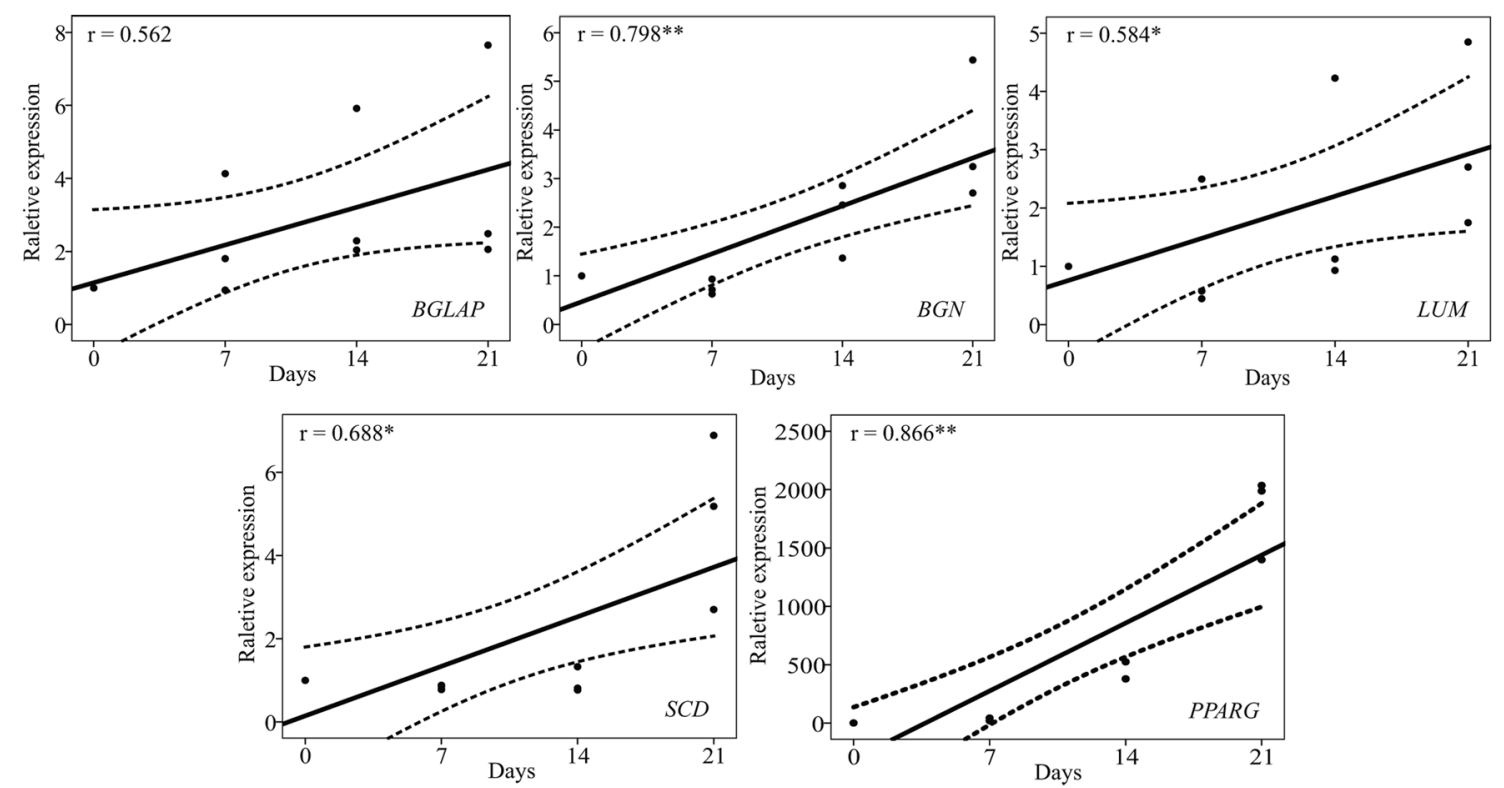

Fig. 5. RT-qPCR analysis: Specific markers were detected by RT-qPCR. Fitted lines represent the correlation between gene expression patterns and induction time for each sample. Dashed lines indicate $95 \%$ confidence intervals. Pearson correlation coefficients $(r)$ are shown. *Correlation with $P<0.05$. **Significant correlation with $P<0.01$.

the culture period. During chondrogenic induction, biglycan $(B G N)$ and lumican $(L U M)$ were significantly upregulated. Expression of adipogenic markers was also analyzed, with the stearoyl-CoA desaturase $(S C D)$
mRNA and peroxisome proliferator-activated receptor gamma $(P P A R G)$ expression levels maximally increased to 7.1- and 2,035-fold, respectively. 


\section{Discussion}

Cell-based therapies rely on cell injection and tissue engineering, and are promising approaches to tissue repair or regeneration. Among all the cell types studied for this purpose, MSCs remain one of the most favorable cell sources because of their easy availability [9, 15, 39, 46]. However, most research on MSCs has been performed on cells derived from bone marrow and adipose tissue. Fetal cells isolated from amniotic fluid can be cultured in vitro for chromosomal, biochemical, and molecular biological analyses [40] and are worthy of research and the recent attention they have received. In this report, we described isolation, cultivation, and characterization of a fibroblast-like population from adult sheep amniotic fluid.

The basic criteria to define human MSCs, provided by the Mesenchymal and Tissue Stem Cell Committee of the International Society for Cellular Therapy, are as follows: (1) plastic adhesion when maintained in standard culture conditions; (2) expression of CD73, CD90, and CD105 and lack of expression of the hematopoietic markers, CD34, CD14 or CD11b, CD79 alpha or CD19, HLA-DR, and CD45 surface molecules; and (3) capable of differentiating into osteoblasts, adipocytes, and chondroblasts in vitro [12]. The isolated MSCs that we obtained easily attached to plastic culture dishes, and therefore they fulfill the plastic adhesion conditions.

We isolated oAF-MSCs that had low generation times and high proliferation capacity, with passage 5 cells entering a plateau phase on the 5th day. MSCs isolated from porcine amniotic fluid enter a plateau phase after the 6th day [5], while those obtained from sheep adipose tissue enter a plateau phase after the 8th day of culture [13]. Ovine bone marrow-derived MSCs enter a plateau phase on the 10th day [34]. Overall, the proliferation ability of MSCs varies between species and tissues. But the proliferative ability was decreased with the increase of passage in oAF-MSCs. This is concordant with previous studies carried out by Colosimo et al [6]. They also showed that the karyotypes obtained by oAF-MSCs at passages 1 and 20 were normal, but they did not report the percentage cells with a normal chromosome pair. We tested 50 cells, and the percentage of cells with a normal chromosome pair was $92 \%$ when cells were subcultured to passage 20 . The adherence of passage 20 cells was enhanced, increasing their digestion time from $1 \mathrm{~min}$ to 3 or $4 \mathrm{~min}$. Colosimo et al suggest that long-term in vitro expansion may cause significant alterations in phenotypic features and plasticity of oAF-MSCs.

It has been reported that hAFSCs express surface antigens including CD117, CD44, CD90, and CD29 but not CD45 and CD34 [28]. MSCs obtained from ovine bone marrow were positive for CD9, CD44, CD54, CD73, CD90, CD105, and CD166 but negative for CD45 [34]. Moreover, oAF-MSCs obtained by Shaw et al. (2011) were strongly positive for CD44, CD58, and CD166 and were negative for CD14, CD31, and CD45 [38]. The cells obtained by Colosimo et al. expressed CD166 antigen at low levels and CD29 and CD58 antigens at intermediate levels but did not display any hematopoietic markers (CD14, CD31, CD45) or the surface antigen CD49f [6]. We also analyzed the MSC phenotype for surface and intracellular markers by immunocytochemistry and obtained oAF-MSCs that were positive for CD29, CD13, CD44, CD90, CD106, and OCT4 and negative for the hematopoietic marker CD45, as are human MSCs.

Colosimo et al. showed that the osteogenic differentiation potential of oAF-MSCs does not drastically change from passage 1 to 20 of during subculture. We examined the potential of oAF-MSCs to differentiate into osteoblasts, chondrocytes, and adipocytes at passage 5 and the variation tendency of differentiation marker gene expression. For osteogenic induction, osteogenic mineralization was confirmed on the last day of osteogenic culture conditions ( 21 days), with calcium salt and calcium node formation shown by $\mathrm{AgNO}_{3}$. BGLAP was upregulated during differentiation (Fig. 5). BGLAP plays a major role in developing osteoblasts [2, 43].

We examined chondrogenesis using Alcian Blue 8GX staining. Stronger blue staining was observed in induced cultures compared with negative controls. The marker genes, $B G N$ and $L U M$, were also analyzed. Biglycan is the protein encoded by $B G N$, and it plays a role in collagen fibril assembly and muscle regeneration. LUM encodes a member of the small leucine-rich proteoglycan (SLRP) family that includes decorin, biglycan, fibromodulin, and osteoglycin, and it may be involved in regulation of collagen fibril organization [30]. During chondrogenic induction, RT-qPCR expression analysis of ovine peripheral blood-derived MSCs did not identify any variation in $B G N$ gene expression levels, but $L U M$ was found to be upregulated on the 21 st day of culture [25]. However, we observed significantly upregulated expression of both genes $(P<0.01$ and $P<0.05$, 
respectively). The difference in the results may be associated with the different cell sources.

Ovine bone marrow-derived MSCs can be differentiated into adipocytes that show cytoplasmic lipid droplets. Adipogenic marker genes have been analyzed previously $[28,34]$. Similarly, we also observed adipogenic differentiation (Fig. 5). We examined expression of two adipogenic markers by RT-qPCR. SCD is expressed uniquely in adipose cells and functions as a crucial element in adipocyte metabolism by catalyzing synthesis of polyunsaturated fatty acids [22]. In our study, $S C D$ expression was upregulated under adipogenic conditions. PPARG is an essential regulator of lipogenesis [1, 37], and PPARG expression was slightly upregulated (7.3fold) in ovine peripheral blood-derived MSCs [25]. In contrast, we found a drastic increase of 2,035-fold in oAF-MSCs under adipogenic induction for 21 days. This discrepancy in results may be attributed to different cell sources or species.

We show that the oAF-MSCs obtained from ovine amniotic fluid are multipotential progenitor cells with the capacity to differentiate into numerous cell types including osteogenic, chondrogenic, and adipogenic cells. These cells express MSC markers and show high expansion capacity. Our findings provide an experimental basis for the research and application of oAF-MSCs in other fields such as sheep transgenic breeding and regenerative medicine.

\section{Acknowledgment}

We thank the College of Life Sciences and Key Laboratory of Mammalian Reproductive Biology and Biotechnology, Ministry of Education, Inner Mongolia University, Hohhot, China. We thank Dr. Xiao Wang and Dr. Zhenhua Dang for technical support. This work was supported by the National Natural Science Foundation of China (No. 31101698) and Inner Mongolia Natural Science Foundation for Distinguished Young Scholars Development (No. 2011JQ03). We are grateful to all colleagues working in the Department of Biology of Inner Mogolia University. We also thank Dr. Rachel James (the editor of Edanz Group, China) for English editing.

\section{References}

1. Aguilar, V., Annicotte, J.S., Escote, X., Vendrell, J., Langin, D., and Fajas, L. 2010. Cyclin G2 regulates adipogenesis through PPAR gamma coactivation. Endocrinology 151: 5247-5254. [Medline] [CrossRef]

2. Aubin, J.E. 1998. Bone stem cells. J. Cell. Biochem. Suppl. 30-31: 73-82. [Medline] [CrossRef]

3. Barker, J.N. and Wagner, J.E. 2003. Umbilical cord blood transplantation: current practice and future innovations. Crit. Rev. Oncol. Hematol. 48: 35-43. [Medline] [CrossRef]

4. Bollini, S., Cheung, K.K., Riegler, J., Dong, X., Smart, N., Ghionzoli, M., Loukogeorgakis, S.P., Maghsoudlou, P., Dubé, K.N., Riley, P.R., Lythgoe, M.F., and De Coppi, P. 2011. Amniotic fluid stem cells are cardioprotective following acute myocardial infarction. Stem Cells Dev. 20: 19851994. [Medline] [CrossRef]

5. Chen, J., Lu, Z., Cheng, D., Peng, S., and Wang, H. 2011. Isolation and characterization of porcine amniotic fluid-derived multipotent stem cells. PLOS ONE 6: e19964. [Medline] [CrossRef]

6. Colosimo, A., Russo, V., Mauro, A., Curini, V., Marchisio, M., Bernabò, N., Alfonsi, M., Mattioli, M., and Barboni, B. 2013. Prolonged in vitro expansion partially affects phenotypic features and osteogenic potential of ovine amniotic fluid-derived mesenchymal stromal cells. Cytotherapy 15: 930-950. [Medline] [CrossRef]

7. Colosimo, A., Curini, V., Russo, V., Mauro, A., Bernabò, N., Marchisio, M., Alfonsi, M., Muttini, A., Mattioli, M., and Barboni, B. 2013. Characterization, GFP gene Nucleofection, and allotransplantation in injured tendons of ovine amniotic fluid-derived stem cells. Cell Transplant. 22: 99-117. [Medline] [CrossRef]

8. D’Alimonte, I., Lannutti, A., Pipino, C., Di Tomo, P., Pierdomenico, L., Cianci, E., Antonucci, I., Marchisio, M., Romano, M., Stuppia, L., Caciagli, F., Pandolfi, A., and Ciccarelli, R. 2013. Wnt signaling behaves as a "master regulator" in the osteogenic and adipogenic commitment of human amniotic fluid mesenchymal stem cells. Stem Cell Rev. 9: 642-654. [Medline] [CrossRef]

9. Dai, K.R., Xu, X.L., Tang, T.T., Zhu, Z.A., Yu, C.F., Lou, J.R., and Zhang, X.L. 2005. Repairing of goat tibial bone defects with BMP-2 gene-modified tissue-engineered bone. Calcif. Tissue Int. 77: 55-61. [Medline] [CrossRef]

10. De Coppi, P., Bartsch, G. Jr., Siddiqui, M.M., Xu, T., Santos, C.C., Perin, L., Mostoslavsky, G., Serre, A.C., Snyder, E.Y., Yoo, J.J., Furth, M.E., Soker, S., and Atala, A. 2007. Isolation of amniotic stem cell lines with potential for therapy. Nat. Biotechnol. 25: 100-106. [Medline] [CrossRef]

11. Dev, K., Giri, S.K., Kumar, A., Yadav, A., Singh, B., and Gautam, S.K. 2012. Derivation, characterization and differentiation of buffalo (Bubalus bubalis) amniotic fluid derived stem cells. Reprod. Domest. Anim. 47: 704-711. [Medline] [CrossRef]

12. Dominici, M., Le Blanc, K., Mueller, I., Slaper-Cortenbach, I., Marini, F., Krause, D., Deans, R., Keating, A., Prockop, D., and Horwitz, E. 2006. Minimal criteria for defining multipotent mesenchymal stromal cells. The International Society for Cellular Therapy position statement. Cytotherapy 8: 315-317. [Medline] [CrossRef]

13. Fadel, L., Viana, B.R., Feitosa, M.L.T., Ercolin, A.C.M., Roballo, K.C.S., Casals, J.B., Pieri, N.C., Meirelles, F.V., Mar- 
tins, D.S., Miglino, M.A., and Ambrósio, C.E. 2011. Protocols for obtainment and isolation of two mesenchymal stem cell sources in sheep. Acta Cir. Bras. 26: 267-273. [Medline] [CrossRef]

14. Fei, X., Jiang, S., Zhang, S., Li, Y., Ge, J., He, B., Goldstein, S., and Ruiz, G. 2013. Isolation, culture, and identification of amniotic fluid-derived mesenchymal stem cells. Cell Biochem. Biophys. 67: 689-694. [Medline] [CrossRef]

15. Gandolfi, F., Vanelli, A., Pennarossa, G., Rahaman, M., Acocella, F., and Brevini, T.A. 2011. Large animal models for cardiac stem cell therapies. Theriogenology 75: 1416-1425. [Medline] [CrossRef]

16. Gang, E.J., Jeong, J.A., Hong, S.H., Hwang, S.H., Kim, S.W., Yang, I.H., Ahn, C., Han, H., and Kim, H. 2004. Skeletal myogenic differentiation of mesenchymal stem cells isolated from human umbilical cord blood. Stem Cells 22: 617-624. [Medline] [CrossRef]

17. Gray, F.L., Turner, C.G., Ahmed, A., Calvert, C.E., Zurakowski, D., and Fauza, D.O. 2012. Prenatal tracheal reconstruction with a hybrid amniotic mesenchymal stem cellsengineered construct derived from decellularized airway. $J$. Pediatr. Surg. 47: 1072-1079. [Medline] [CrossRef]

18. Guo, X., Wang, C., Duan, C., Descamps, M., Zhao, Q., Dong, L., Lü, S., Anselme, K., Lu, J., and Song, Y.Q. 2004. Repair of osteochondral defects with autologous chondrocytes seeded onto bioceramic scaffold in sheep. Tissue Eng. 10: 1830-1840. [Medline] [CrossRef]

19. Iacono, E., Cunto, M., Zambelli, D., Ricci, F., Tazzari, P.L., and Merlo, B. 2012. Could fetal fluid and membranes be an alternative source for mesenchymal stem cells (MSCs) in the feline species? A preliminary study. Vet. Res. Commun. 36: 107-118. [Medline] [CrossRef]

20. Karahuseyinoglu, S., Cinar, O., Kilic, E., Kara, F., Akay, G.G., Demiralp, D.O., Tukun, A., Uckan, D., and Can, A. 2007. Biology of stem cells in human umbilical cord stroma: in situ and in vitro surveys. Stem Cells 25: 319-331. [Medline] [CrossRef]

21. Kern, S., Eichler, H., Stoeve, J., Klüter, H., and Bieback, K. 2006. Comparative analysis of mesenchymal stem cells from bone marrow, umbilical cord blood, or adipose tissue. Stem Cells 24: 1294-1301. [Medline] [CrossRef]

22. Kim, Y.C. and Ntambi, J.M. 1999. Regulation of stearoylCoA desaturase genes: role in cellular metabolism and preadipocyte differentiation. Biochem. Biophys. Res. Commun. 266: 1-4. [Medline] [CrossRef]

23. Li, Y., Cang, M., Lee, A.S., Zhang, K., and Liu, D. 2011. Reprogramming of sheep fibroblasts into pluripotency under a drug-inducible expression of mouse-derived defined factors. PLoS ONE 6: e15947. [Medline] [CrossRef]

24. Lovati, A.B., Corradetti, B., Lange Consiglio, A., Recordati, C., Bonacina, E., Bizzaro, D., and Cremonesi, F. 2011. Comparison of equine bone marrow-, umbilical cord matrix and amniotic fluid-derived progenitor cells. Vet. Res. Commun. 35: 103-121. [Medline] [CrossRef]

25. Lyahyai, J., Mediano, D.R., Ranera, B., Sanz, A., Remacha, A.R., Bolea, R., Zaragoza, P., Rodellar, C., and Martín-Burriel, I. 2012. Isolation and characterization of ovine mesenchymal stem cells derived from peripheral blood. BMC Vet.
Res. 8: 169. [Medline] [CrossRef]

26. Mauro, A., Turriani, M., Ioannoni, A., Russo, V., Martelli, A., Di Giacinto, O., Nardinocchi, D., and Berardinelli, P. 2010. Isolation, characterization, and in vitro differentiation of ovine amniotic stem cells. Vet. Res. Commun. 34: S25S28. [Medline] [CrossRef]

27. Morigi, M. and De Coppi, P. 2014. Cell therapy for kidney injury: different options and mechanisms-mesenchymal and amniotic fluid stem cells. Nephron, Exp. Nephrol. 126: 59. [Medline] [CrossRef]

28. Mrugala, D., Bony, C., Neves, N., Caillot, L., Fabre, S., Moukoko, D., Jorgensen, C., and Noël, D. 2008. Phenotypic and functional characterisation of ovine mesenchymal stem cells: application to a cartilage defect model. Ann. Rheum. Dis. 67: 288-295. [Medline] [CrossRef]

29. Piccoli, M., Franzin, C., Bertin, E., Urbani, L., Blaauw, B., Repele, A., Taschin, E., Cenedese, A., Zanon, G.F., AndréSchmutz, I., Rosato, A., Melki, J., Cavazzana-Calvo, M., Pozzobon, M., and De Coppi, P. 2012. Amniotic fluid stem cells restore the muscle cell niche in a HSA-Cre, Smn(F7/ F7) mouse model. Stem Cells 30: 1675-1684. [Medline] [CrossRef]

30. Pietraszek, K., Chatron-Colliet, A., Brézillon, S., Perreau, C., Jakubiak-Augustyn, A., Krotkiewski, H., Maquart, F.X., and Wegrowski, Y. 2014. Lumican: a new inhibitor of matrix metalloproteinase-14 activity. FEBS Lett. 588: 4319-4324. [Medline] [CrossRef]

31. Pountos, I. and Giannoudis, P.V. 2005. Biology of mesenchymal stem cells. Injury 36:(Suppl 3): S8-S12. [Medline] [CrossRef]

32. Pountos, I., Jones, E., Tzioupis, C., McGonagle, D., and Giannoudis, P.V. 2006. Growing bone and cartilage. The role of mesenchymal stem cells. J. Bone Joint Surg. Br. 88: 421426. [Medline] [CrossRef]

33. Li, Q., Fan, Y., Sun, X., and Yu, Y. 2013. Generation of induced pluripotent stem cells from human amniotic fluid cells by reprogramming with two factors in feeder-free conditions. J. Reprod. Dev. 59: 72-77 10.1262/jrd.2012-109. [Medline]

34. Rentsch, C., Hess, R., Rentsch, B., Hofmann, A., Manthey, S., Scharnweber, D., Biewener, A., and Zwipp, H. 2010. Ovine bone marrow mesenchymal stem cells: isolation and characterization of the cells and their osteogenic differentiation potential on embroidered and surface-modified polycaprolactone-co-lactide scaffolds. In Vitro Cell. Dev. Biol. Anim. 46: 624-634. [Medline] [CrossRef]

35. Scheerlinck, J.P.Y., Snibson, K.J., Bowles, V.M., and Sutton, P. 2008. Biomedical applications of sheep models: from asthma to vaccines. Trends Biotechnol. 26: 259-266. [Medline] [CrossRef]

36. Secco, M., Zucconi, E., Vieira, N.M., Fogaça, L.L.Q., Cerqueira, A., Carvalho, M.D., Jazedje, T., Okamoto, O.K., Muotri, A.R., and Zatz, M. 2008. Multipotent stem cells from umbilical cord: cord is richer than blood! Stem Cells 26: 146-150. [Medline] [CrossRef]

37. Seo, J.B., Moon, H.M., Kim, W.S., Lee, Y.S., Jeong, H.W., Yoo, E.J., Ham, J., Kang, H., Park, M.G., Steffensen, K.R., Stulnig, T.M., Gustafsson, J.A., Park, S.D., and Kim, J.B. 2004. Activated liver X receptors stimulate adipocyte dif- 
ferentiation through induction of peroxisome proliferatoractivated receptor gamma expression. Mol. Cell. Biol. 24: 3430-3444. [Medline] [CrossRef]

38. Shaw, S.W., Bollini, S., Nader, K.A., Gastadello, A., Mehta, V., Filppi, E., Cananzi, M., Gaspar, H.B., Qasim, W., De Coppi, P., and David, A.L. 2011. Autologous transplantation of amniotic fluid-derived mesenchymal stem cells into sheep fetuses. Cell Transplant. 20: 1015-1031. [Medline] [CrossRef]

39. Silva, G.V., Litovsky, S., Assad, J.A., Sousa, A.L., Martin, B.J., Vela, D., Coulter, S.C., Lin, J., Ober, J., Vaughn, W.K., Branco, R.V., Oliveira, E.M., He, R., Geng, Y.J., Willerson, J.T., and Perin, E.C. 2005. Mesenchymal stem cells differentiate into an endothelial phenotype, enhance vascular density, and improve heart function in a canine chronic ischemia model. Circulation 111: 150-156. [Medline] [CrossRef]

40. Steele, M.W. and Breg, W.R. Jr. 1966. Chromosome analysis of human amniotic-fluid cells. Lancet 1: 383-385. [Medline] [CrossRef]

41. Zhang, T., Wang, Z., Li, B., Shi, J., Qin, Y., and Liu, D. 2010. Molecular Cloning and Characterization Analysis of LEF-1 Gene from Inner Mongolia Cashmere Goat. 3rd International Conference on Biomedical Engineering and Informatics. 978-1-4244-6498-2/10.

42. Turner, C.G., Klein, J.D., Steigman, S.A., Armant, M., Nicksa, G.A., Zurakowski, D., Ritz, J., and Fauza, D.O. 2011. Preclinical regulatory validation of an engineered diaphragmatic tendon made with amniotic mesenchymal stem cells.
J. Pediatr. Surg. 46: 57-61. [Medline] [CrossRef]

43. Valenti, M.T., Dalle Carbonare, L., Donatelli, L., Bertoldo, F., Zanatta, M., and Lo Cascio, V. 2008. Gene expression analysis in osteoblastic differentiation from peripheral blood mesenchymal stem cells. Bone 43: 1084-1092. [Medline] [CrossRef]

44. Wadlow, R.C. and Porter, D.L. 2002. Umbilical cord blood transplantation: where do we stand? Biol. Blood Marrow Transplant. 8: 637-647. [Medline] [CrossRef]

45. Yan, Z., Ma, Y.Z., Liu, D.J., Cang, M., Wang, R., and Bao, S. 2010. Targeted suppression of connexin 43 in ovine preimplantation embryos by RNA interference using long doublestranded RNA. Asian-Aust. J. Anim. Sci. 23: 456-464.

46. Zscharnack, M., Hepp, P., Richter, R., Aigner, T., Schulz, R., Somerson, J., Josten, C., Bader, A., and Marquass, B. 2010. Repair of chronic osteochondral defects using predifferentiated mesenchymal stem cells in an ovine model. Am. J. Sports Med. 38: 1857-1869. [Medline] [CrossRef]

47. Zscharnack, M., Poesel, C., Galle, J., and Bader, A. 2009. Low oxygen expansion improves subsequent chondrogenesis of ovine bone-marrow-derived mesenchymal stem cells in collagen type I hydrogel. Cells Tissues Organs Print 190: 81-93. [Medline] [CrossRef]

48. Zuk, P.A., Zhu, M., Ashjian, P., De Ugarte, D.A., Huang, J.I., Mizuno, H., Alfonso, Z.C., Fraser, J.K., Benhaim, P., and Hedrick, M.H. 2002. Human adipose tissue is a source of multipotent stem cells. Mol. Biol. Cell 13: 4279-4295. [Medline] [CrossRef] 